\title{
Natural history of hypertrophic cardiomyopathy
}

\author{
P Spirito, P Bellone
}

Since 1958, when Donald Teare first recognised and described hypertrophic cardiomyopathy in eight patients, ${ }^{1}$ many studies have confirmed his initial observations and have substantially increased our understanding of the pathophysiology of this disease. The clinical course of individual patients, however, is extremely heterogeneous and the natural history of the disease has yet to be defined. Therefore, clinical management and assessment of prognosis in individual patients remain difficult and riddled with uncertainties.

In recent years, evidence has emerged that substantial remodelling of left ventricular morphology occurs in patients with hypertrophic cardiomyopathy during the natural course of the disease. In the present review we focus on this aspect of hypertrophic cardiomyopathy and its influence on the natural history of the disease. We also discuss some uncertainties and controversies regarding the clinical course and prognosis of the general population of patients with hypertrophic cardiomyopathy.
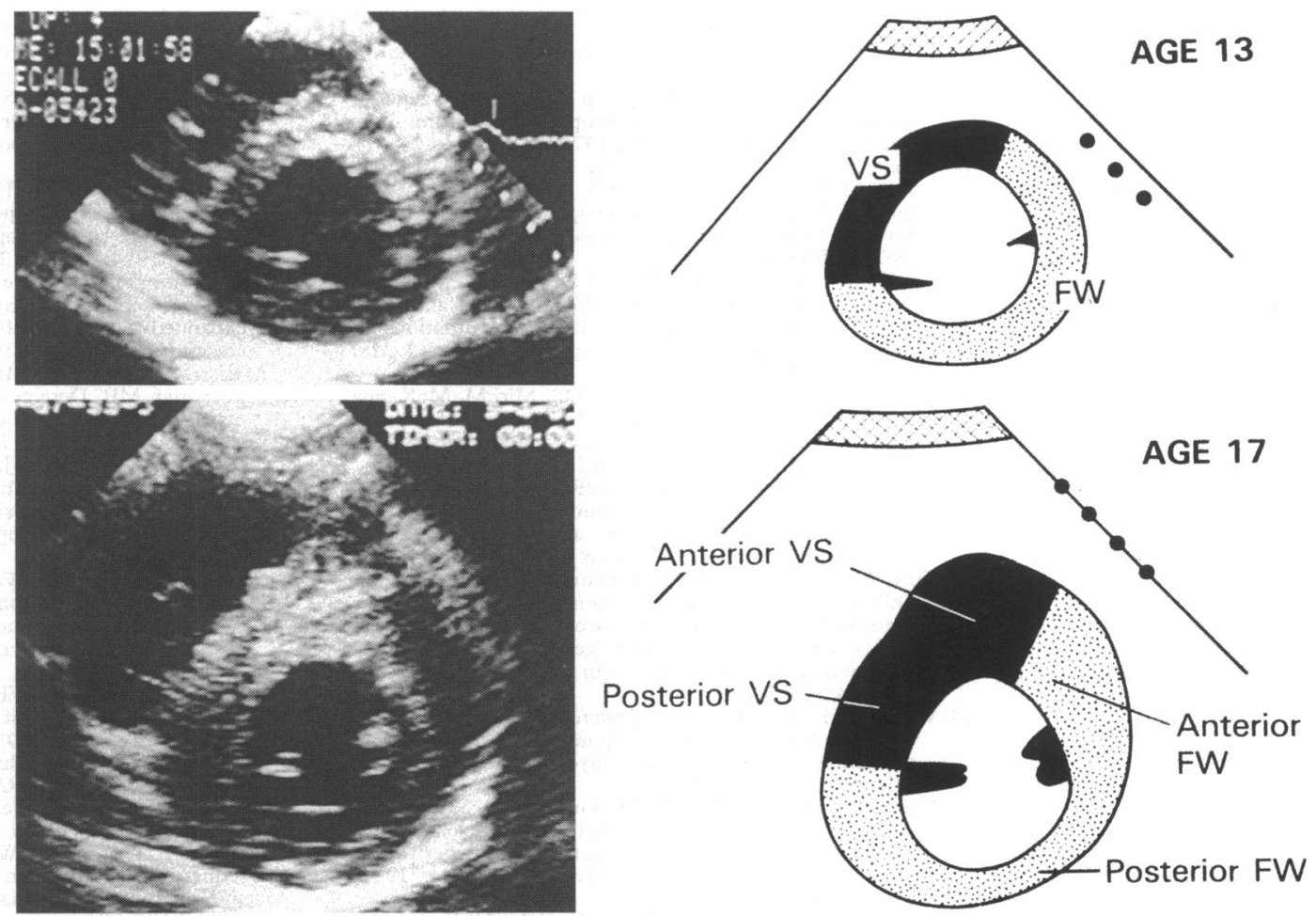

Figure 1 Stop frame cross sectional echocardiograms at end diastole obtained in a girl with a family history of hypertrophic cardiomyopathy. At age 13 the lefi ventricular wall was of normal thickness; at age 17, at the same cross sectional level, the anterior ventricular septum and contiguous regions of the anterior free wall and posterior septum showed a pronounced increase in thickness. FW, free wall; VS, ventricular septum. (Reproduced with permission of New England fournal of Medicine from Maron BF, et al. Development and progression of left ventricular hypertrophy in children with hypertrophic cardiomyopathy. $N$ Engl f Med 1986;315:610-4.

\section{Left ventricular remodelling}

Severe asymmetrical left ventricular hypertrophy in the presence of a small left ventricular cavity is the hallmark of hypertrophic cardiomyopathy. These morphological fea, however, can change substantially during the patient's life. There can be a marked increase in left ventricular wall thickness with a of the left ventricular wall with an increase in cavity size.

Progression of left ventricular hypertrophy Per three to six years was identified in $>70 \%$ of children with hypertrophic cardiomyopathy. ${ }^{2}$ In many the progression of hypertrophy as striking, with increases in wall thickness more than $20 \mathrm{~mm}$ (250\%) (fig 1). This iderable progression of hypertrophy was most of the children remained symptom free. Remodelling of left ventricular morphology and geometry during childhood can also lead to changes in the haemodynamics of the disease. Recent data have shown that children
Divisione di

Cardiologia, Ente Ospedaliero Ospedali P Spirito P Bellone

Correspondence to: Dr Paolo Spirito, Divisione di Cardiologia, Ente

Galliera, Via Volta 8, 16128

Genoa, Italy. 
with hypertrophic cardiomyopathy in whom the increase in wall thickness leads to a substantial decrease in the size of the left ventricular outflow tract and to anterior displacement of the mitral valve develop systolic anterior motion of the mitral leaflets and dynamic obstruction to outflow. ${ }^{3}$

Whereas progression of left ventricular hypertrophy is common in children, particularly during adolescence, it has not been identified in adults. ${ }^{4}$ The fact that progression of hypertrophy is confined to a period of rapid body growth suggests that the factors that are responsible for growth and development during childhood may have an important role in this increase in left ventricular wall thickness.

In adults left ventricular morphology can also change substantially, but in an opposite direction to that seen in children. In adults, left ventricular remodelling results from progressive left ventricular wall thinning and cavity dilatation (fig 2). The first investigation on this subject identified a subset of patients with hypertrophic cardiomyopathy who had only mild and localised hypertrophy, but severe symptoms of heart failure..$^{5}$ Most had both systolic and diastolic dysfunction. Subsequent studies showed that this "mild but malignant" hypertrophy was the result of progressive thinning of the left ventricular wall. ${ }^{46}$ These changes in wall thickness are also associated with a progressive increase in left ventricular cavity dimension, but absolute left ventricular dilatation is rare. Marked wall thinning, relative cavity dilatation, and systolic dysfunction have been reported in about $10 \%$ of patients with hypertrophic cardiomyopathy and moderate to severe symptoms. ${ }^{6}$ Therefore, this malignant morphological evolution with extensive left ventricular remodelling occurs in a significant minority of patients with symptoms.

In a recent study, an inverse relation was identified between left ventricular wall thickness and age in hypertrophic cardiomyopathy, with older patients having considerably less severe hypertrophy than younger patients. ${ }^{7}$ A higher rate of death in patients with
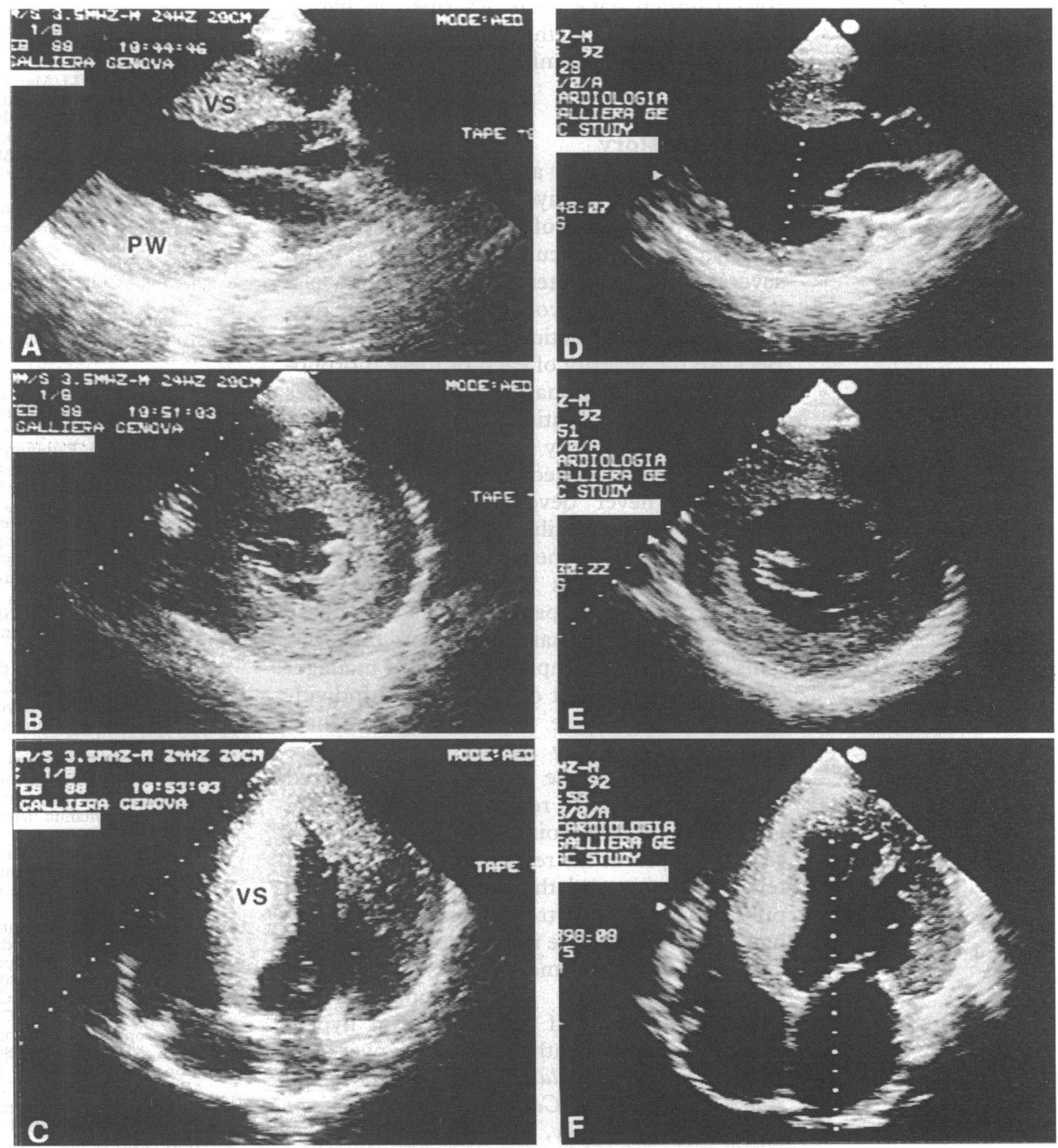

Figure 2 Stop frames of the initial cross sectional echocardiogram $(A, B$, and $C)$ and of the most recent cross sectional echocardiogram $(D, E$, and $F$ ) obtained during diastole in a patient with hypertrophic cardiomyopathy who showed progressive left ventricular wall thinning and cavity dilatation. $(A-C)$ Age 19 years; septal thickness and posterior wall thickness $32 \mathrm{~mm}$, left ventricular diastolic cavity dimension $42 \mathrm{~mm}$ (D-E) A ge 23 years; septal thickness and posterior wall thickness much reduced (to 22 and $18 \mathrm{~mm}$, respectively) and the left ventricular cavity dilated (to $70 \mathrm{~mm}$ ). $P W$, posterior left ventricular free wall; VS, ventricular septum. 
pronounced hypertrophy can not be the sole explanation for this finding, because premature death is uncommon in patients with hypertrophic cardiomyopathy and is not confined to young patients with marked hypertrophy. An alternative, but not mutually exclusive, explanation for this finding is that there is mild and progressive wall thinning over a long time in many patients with hypertrophic cardiomyopathy.

At necropsy, the hearts of patients with wall thinning and cavity dilatation show diffuse left ventricular scarring, usually of both the septum and the left ventricular free wall. The mechanisms responsible for myocardial scarring and wall thinning in hypertrophic cardiomyopathy have not been established. It is likely, however, that chronic ischaemia plays an important part in scarring. Several studies have shown myocardial ischaemia in hypertrophic cardiomyopathy..$^{8-10}$ Ischaemia could be caused by inadequate capillary density relative to the increased myocardial mass. In addition, abnormal intramyocardial arterioles with thickened walls and an apparently narrowed lumen have been described in hypertrophic cardiomyopathy ${ }^{11}$ and may contribute to myocardial ischaemia.

\section{Natural history}

The clinical course and natural history of hypertrophic cardiomyopathy is the result of a complex interaction of left ventricular hypertrophy, left ventricular remodelling, and several functional alterations including diastolic impairment, myocardial ischaemia, outflow tract obstruction, and arrhythmias. Because the severity of each of these morphological and functional abnormalities varies greatly in different patients, the clinical course and natural history of the disease are extremely heterogeneous. In some patients symptoms never develop, in some severe symptoms of heart failure develop, and others die suddenly and unexpectedly often in the absence of previous cardiac symptoms. ${ }^{12-14}$ The percentages of patients in each of these three categories remain unknown, however. This uncertainty complicates clinical management and assessment of prognosis in individual patients. There is indirect evidence, however, that many patients have a more benign clinical course than could be inferred from most published reports. This conclusion is based on several points. Most patients with severe symptoms are referred to a few selected tertiary centres and the majority of the data published on hypertrophic cardiomyopathy have come from these referral institutions and constitute, in large measure, what we know about hypertrophic cardiomyopathy. For example, almost half the studies on hypertrophic cardiomyopathy published over a 5 year period in Circulation, the fournal of the American College of Cardiology, the American fournal of Cardiology, and the British Heart fournal came from only two centres. ${ }^{15}$ In addition, more than $90 \%$ of the patients reported to have severe symptoms came from the same two institutions. Because these referral centres see the most critically ill patients and publish many studies on hypertrophic cardiomyopathy, it is likely that the image of the disease that is projected into published reports is worse than the "real disease" in the overall patient population. This conclusion is also supported by the results of genetic studies performed on large numbers of families with hypertrophic cardiomyopathy. In a study in which almost 300 relatives of patients with hypertrophic cardiomyopathy were systematically investigated, a quarter of the relatives were found to be affected. ${ }^{16}$ More than $70 \%$ of these relatives were symptom free. Therefore, many affected family members are symptom free and often unaware of the disease. Indeed, recent studies based on patients from non-referral centres ${ }^{15-17}$ reported mortality for hypertrophic cardiomyopathy that was substantially lower than the generally quoted figures of $3-4 \%$ a year. ${ }^{12-14}$

1 Teare D. Asymmetrical hypertrophy of the heart in young adults. Br Heart $\mathcal{F} 1958 ; 20: 1-8$.

2 Maron BJ, Spirito P, Wesley Y, Arce J. Development or progression of left ventricular hypertrophy in children with hypertrophic cardiomyopathy: identification by 315:610-4.

3 Panza JA, Maris TJ, Maron BJ. Development and determinants of dynamic obstruction to left ventricular outflow in young patients with hypertrophic cardiomyopathy. $\mathcal{f}$ Am Coll Cardiol 1989;13:820-3.

4 Spirito P, Maron BJ. Absence of progression of left ventricular hypertrophy in adult patients with hyperventricular hypertrophy in adult patients with hype

5 Spirito P, Maron BJ, Bonow RO, Epstein SE. Severe functional limitation in patients with hypertrophic cardiomyopathy and only mild localized left ventricular hypertrophy. I Am Coll Cardiol 1986;8:537-44.

6 Spirito P, Maron BJ, Bonow RO, Epstein SE. Occurrence and significance of progressive left ventricular wall thinning and relative cavity dilatation in patients with hypertrophic cardiomyopathy. Am $\mathcal{f}$ Cardiol 1987;60: 123-9.

7 Spirito P, Maron BJ. Relation between extent of left ventricular hypertrophy and age in hypertrophic cardiomyopathy. F Am Coll Cardiol 1989;13:820-3.

8 Pasternac A, Noble J, Steulens Y, Elie R, Henschke C, Bourassa MG. Pathophysiology of chest pain in patients with cardiomyopathies and normal coronary arteries. with cardiomyopathies and
Circulation 1982;65:778-89.

9 Cannon RO, Rosing DR, Maron BJ, Leon MB, Bonow RO, Watson RM, Epstein SE. Myocardial ischemia in patients with hypertrophic cardiomyopathy: contribution of inadequate vasodilator reserve and elevated left ventricular filling pressures. Circulation 1985;71:234 43.

10 O'Gara PT, Bonow RO, Maron BJ, Damske BA, Van Lingen A, Bacharach SL, et al. Myocardial perfusion abnormalities in patients with hypertrophic cardiomyopathy: assessment with thallium-201 emission computed tomography. Circulation 1987;76:1214-23.

11 Maron BJ, Wolfson JK, Epstein SE, Roberts WC. Intramural ("small vessel") coronary artery disease in hypertrophic cardiomyopathy. I Am Coll Cardiol 1986; 8:545-57.

12 McKenna WJ, Deanfield J, Faruqui A, England D, Oakley CM, Goodwin JF. Prognosis in hypertrophic cardiomyopathy: role of age, and clinical, electrocardiographic myopathy: role of age, and clinical, electrocardiographic and he-8.

13 Wingle ED, Sasson Z, Henderson MA, et al. Hypertrophic cardiomyopathy: the importance of the site and the extent of hypertrophy: a review. Prog Cardiovasc Dis 1985;28:1-83.

14 Maron BJ, Bonow RO, Cannon RO III, Leon MB, Epstein SE. Hypertrophic cardiomyopathy: interrelations of clinical manifestations, pathophysiology, and therapy. $N$ Engl ₹ Med 1987;316:780-9, 844-52.

15 Spirito $P$, Chiarella F, Carratino L, Zoni Berisso M, Bellotti P, Vecchio C. Clinical course and prognosis of hypertrophic cardiomyopathy in an outpatient population. N Engl f Med 1989;320:749-55.

16 Maron BJ, Nichols PF III, Pickle LW, Wesley YE, Mulvihill JJ. Patterns of inheritance in hypertrophic cardiomyopathy: assessment by $M$-mode and two-dimen1087-94.

17 Kofflard MJ, Waldstein DJ, Vos J, ten Cate FJ. Prognosis in hypertrophic cardiomyopathy: long-term follow-up in a hypertrophic cardiomyopathy: long-term follow-up in a
large, unselected outpatient population. Am $\mathcal{f}$ Cardiol (in large, unse.
press). 